Supporting Information for:

\title{
Digallium Sites Are Formed in the Reaction of Trimethylgallium with Silica
}

\author{
Ziyad A. Taha, ${ }^{1}$ Eric W. Deguns, ${ }^{2}$ Swarup Chattopadhyay ${ }^{1}$ and Susannah L. Scott ${ }^{1,2 *}$ \\ Departments of Chemical Engineering ${ }^{1}$ and Chemistry ${ }^{2}$ \\ University of California, Santa Barbara, CA 93106-5080
}

Table of Contents:

Page

Figure S1. Low frequency IR spectrum of $\mathrm{GaMe}_{3}$-modified A380-500 $\quad$ S2

$\begin{array}{lll}\text { Table S1. Infrared assignments for } \mathrm{GaMe}_{3} \text {-modified silica } & \text { S2 }\end{array}$

Figure S2. Room temperature IR spectra of A380 silica (a) after thermal S3 pretreatment at $100^{\circ} \mathrm{C}$; (b) after reaction with excess $\mathrm{GaMe}_{3}$; and

(c) after exposure of the $\mathrm{GaMe}_{3}$-modified silica to excess water vapor at $200^{\circ} \mathrm{C}$, in the $v(\mathrm{O}-\mathrm{H})$ and $v(\mathrm{C}-\mathrm{H})$ regions.

Figure S3. EXAFS for $\mathrm{GaMe}_{3}$-modifed A380-500, curve-fit to model A $\quad$ S4

$\begin{array}{lll}\text { Table S2. } & \text { Fit parameters for Figure S3 } & \text { S4 }\end{array}$

Figure S4. EXAFS for $\mathrm{GaMe}_{3}$-modifed A380-500, curve-fit to model B $\quad$ S5

Table S3. Fit parameters for Figure S4 S5

Figure S5. EXAFS data for $\left[\mathrm{GaMe}_{2}\left(\mu-\mathrm{OSiPh}_{3}\right)\right]_{2}$, with curve-fit including $\quad \mathrm{S} 6$ Ga-Si path

$\begin{array}{lll}\text { Table S4. } & \text { Fit parameters for Figure S5 } & \text { S6 }\end{array}$

Figure S6. EXAFS for $\mathrm{GaMe}_{3}$-modified A380-500, curve-fit to model C, S7 with refinement of coordination numbers

$\begin{array}{lll}\text { Table S5. } & \text { Fit parameters for Figure S6 } & \text { S7 }\end{array}$

Figure S7. EXAFS for $\mathrm{GaMe}_{3}$-modified A380-100, curve-fit to model C S8

$\begin{array}{lll}\text { Table S6. } & \text { Fit parameters for Figure S6 } & \text { S8 }\end{array}$ 


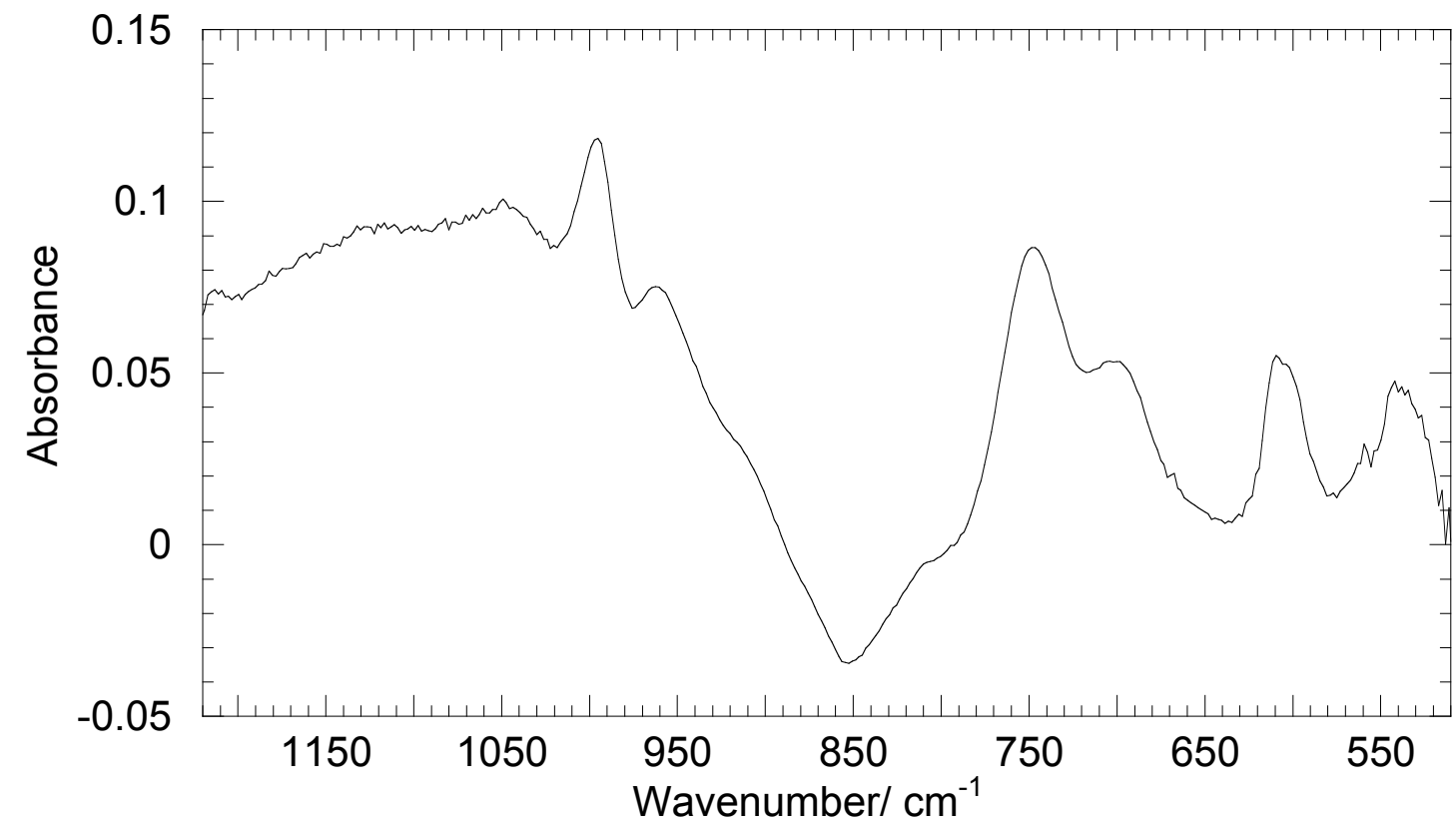

Figure S1. IR difference spectrum of a thin film of A380-500 silica, modified with $\mathrm{GaMe}_{3}$. The spectrum of the silica pellet has been removed by subtraction.

Table S1. Infrared vibrations and their assignments for $\mathrm{GaMe}_{3}$-modified A380

\begin{tabular}{cc}
\hline peak position $/ \mathrm{cm}^{-1}$ & assignment $^{\mathrm{a}}$ \\
\hline 2968 & $v_{\mathrm{as}}\left(\mathrm{CH}_{3}\right)$ \\
2914 & $v_{\mathrm{s}}\left(\mathrm{CH}_{3}\right)$ \\
2407 & $2 \delta_{\mathrm{s}}\left(\mathrm{CH}_{3}\right)$ \\
1420 & $\delta_{\mathrm{as}}\left(\mathrm{CH}_{3}\right)$ \\
1214 & $\delta_{\mathrm{s}}\left(\mathrm{CH}_{3}\right)$ \\
995 & $v_{\mathrm{as}}\left(\mathrm{SiOGa}^{\mathrm{b}}\right)$ \\
962 & $\mathrm{~b}$ \\
747 & $\rho\left(\mathrm{CH}_{3}\right)$ \\
699 & $\rho\left(\mathrm{CH}_{3}\right)$ \\
620 & $v_{\mathrm{as}}\left(\mathrm{GaC}_{2}\right)$ \\
544 & $v_{\mathrm{s}}\left(\mathrm{GaC}_{2}\right)$ \\
\hline
\end{tabular}

${ }^{a}$ Morrow, B. A.; McFarlane, R. A. J. Phys. Chem. 1986, 90, 3192-3197.

${ }^{\mathrm{b}}$ May be an artifact due to the disappearance of the $v_{\mathrm{s}}(\mathrm{Si}-\mathrm{OH})$ mode at $980 \mathrm{~cm}^{-1}$. 

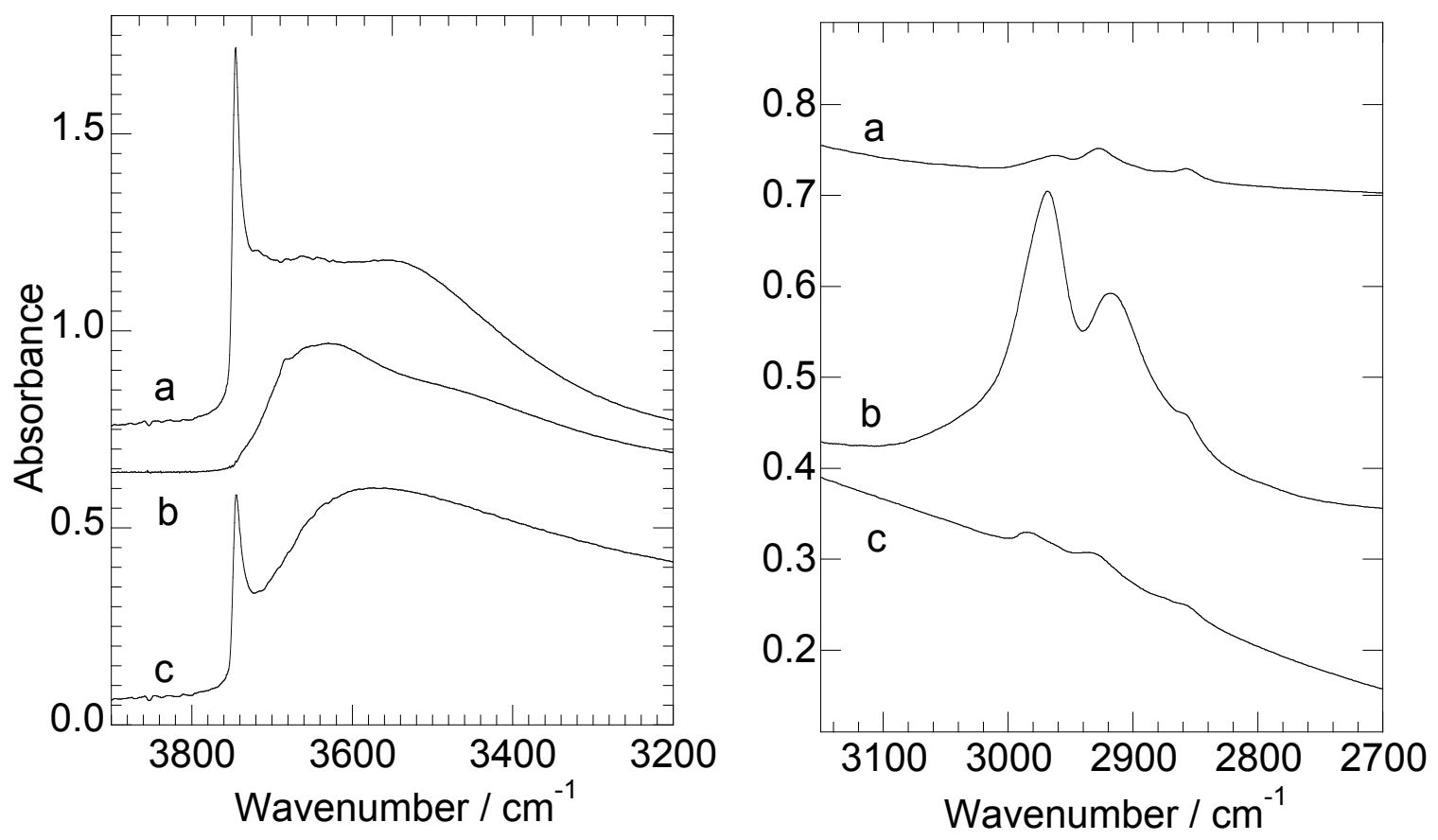

Figure S2. Room temperature IR spectra of A380 silica (a) after thermal pretreatment at $100^{\circ} \mathrm{C}$; (b) after reaction with excess $\mathrm{GaMe}_{3}$; and (c) after exposure of the $\mathrm{GaMe}_{3}$-modified silica to excess water vapor at $200^{\circ} \mathrm{C}$, in the $v(\mathrm{O}-\mathrm{H})$ and $v(\mathrm{C}-\mathrm{H})$ regions. All spectra were recorded under vacuum, after removal of volatiles, and are vertically offset for clarity. 

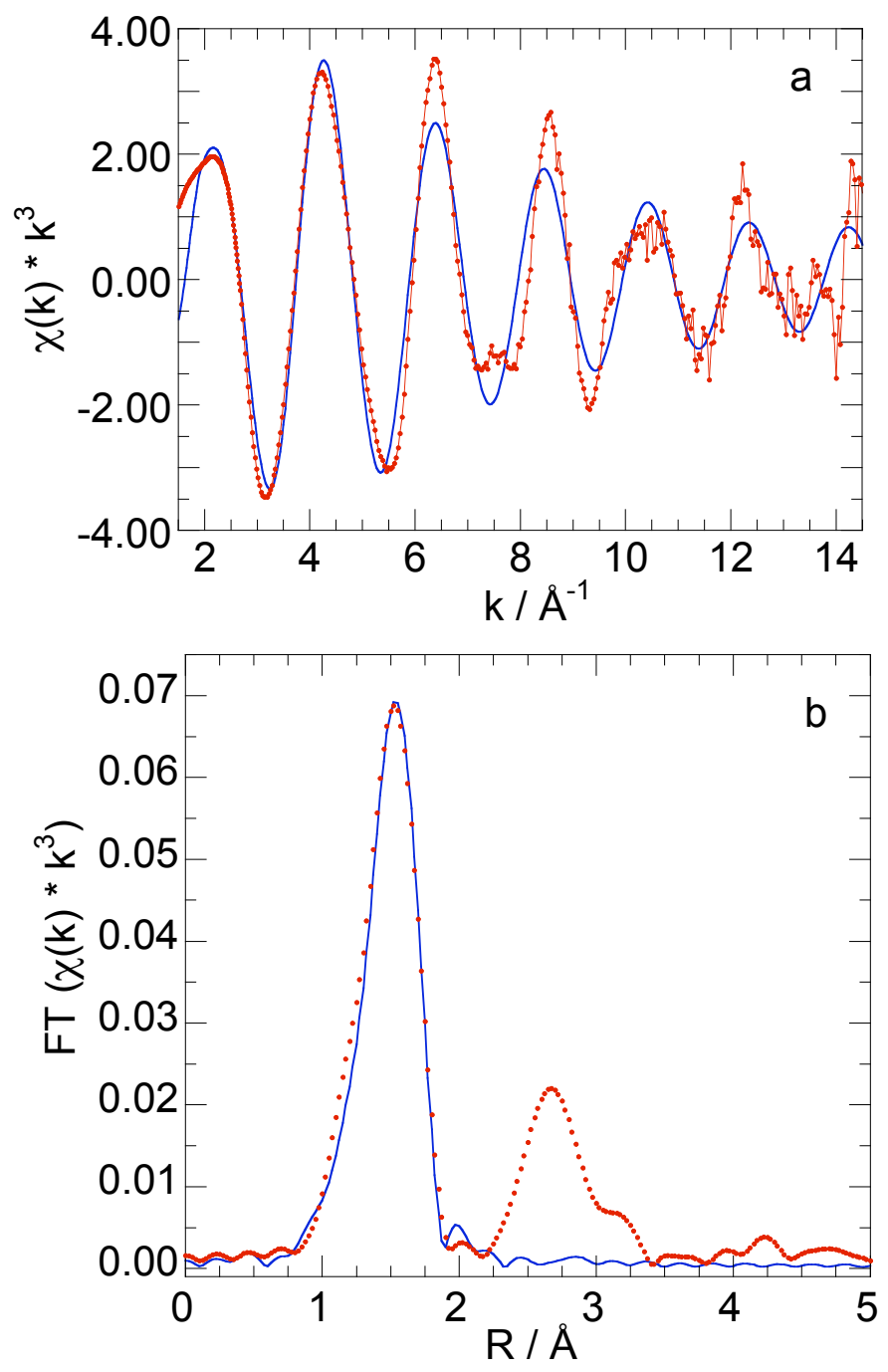

Figure S3. EXAFS data (red points) in $\mathrm{k}^{3}$-weighted k-space (a) and non-phasecorrected R-space (b), for $\mathrm{GaMe}_{3}$-modifed A380-500. Parameters for the curve-fit (blue lines) to model $\mathbf{A}, \equiv \mathrm{SiOGaMe}_{2}$, are given in Table S2.

Table S2. Parameters from the EXAFS curve-fit for $\mathrm{GaMe}_{3}$-modifed A380-500, as shown in Figure S3, to the single-scattering model $\mathbf{A}, \equiv \mathrm{SiOGaMe}_{2}{ }^{\text {a }}$

\begin{tabular}{lcccc}
\hline path & $\mathrm{N}^{\mathrm{b}}$ & $\mathrm{R}(\AA)$ & $\sigma^{2}\left(\AA^{2}\right)$ & $\Delta \mathrm{E}_{0}(\mathrm{eV})$ \\
\hline Ga-O & 1 & 1.97 & -0.0010 & 0.23 \\
Ga-C & 1 & 1.96 & 0.0060 & 4.99 \\
Ga-C & 1 & 1.95 & 0.0075 & 4.99 \\
\hline
\end{tabular}

${ }^{\mathrm{a}} \mathrm{S}_{0}{ }^{2}=0.793$. Residual $=8.63$. Note the physically impossible value of the Debye-Waller factor $\sigma^{2}$ for the Ga-O path.

${ }^{\mathrm{b}}$ Coordination numbers were fixed at integer values during fit refinement. 

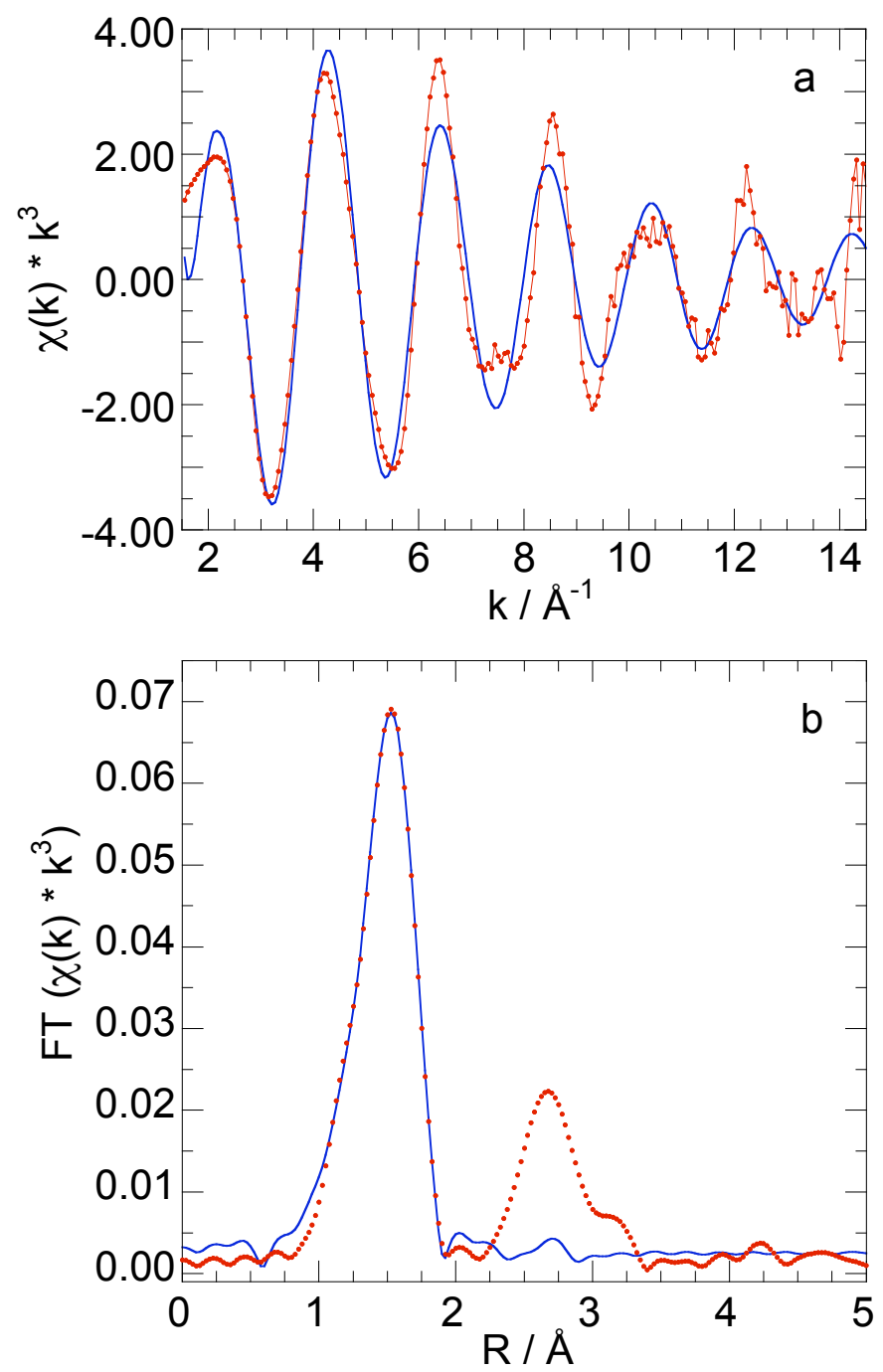

Figure S4. EXAFS data (red points) in $\mathrm{k}^{3}$-weighted k-space (a) and non-phasecorrected R-space (b), for $\mathrm{GaMe}_{3}$-modifed A380-500. Parameters for the curve-fit (blue lines) to model $\mathbf{B},(\equiv \mathrm{SiO})\left(\equiv \mathrm{Si}_{2} \mathrm{O}\right) \mathrm{GaMe}_{2}$, are given in Table S3.

Table S3. Parameters from the EXAFS curve-fit for $\mathrm{GaMe}_{3}$-modifed A380-500, as shown in Figure S4, to the single-scattering model B, $(\equiv \mathrm{SiO})\left(\equiv \mathrm{Si}_{2} \mathrm{O}\right) \mathrm{GaMe}_{2}{ }^{\text {a }}$

\begin{tabular}{lcccc}
\hline path & $\mathrm{N}^{\mathrm{b}}$ & $\mathrm{R}(\AA)$ & $\sigma^{2}\left(\AA^{2}\right)$ & $\Delta \mathrm{E}_{0}(\mathrm{eV})$ \\
\hline $\mathrm{Ga}-\mathrm{O}$ & 1 & 1.97 & 0.0042 & 4.06 \\
$\mathrm{Ga}-\mathrm{C}$ & 2 & 1.94 & 0.0036 & 0.47 \\
$\mathrm{Ga}-\mathrm{O}$ & 1 & 1.98 & 0.0060 & 4.06 \\
\hline
\end{tabular}

${ }^{\mathrm{a}} \mathrm{S}_{0}{ }^{2}=0.813$. Residual $=6.98$.

${ }^{\mathrm{b}}$ Coordination numbers were fixed at integer values during fit refinement. 

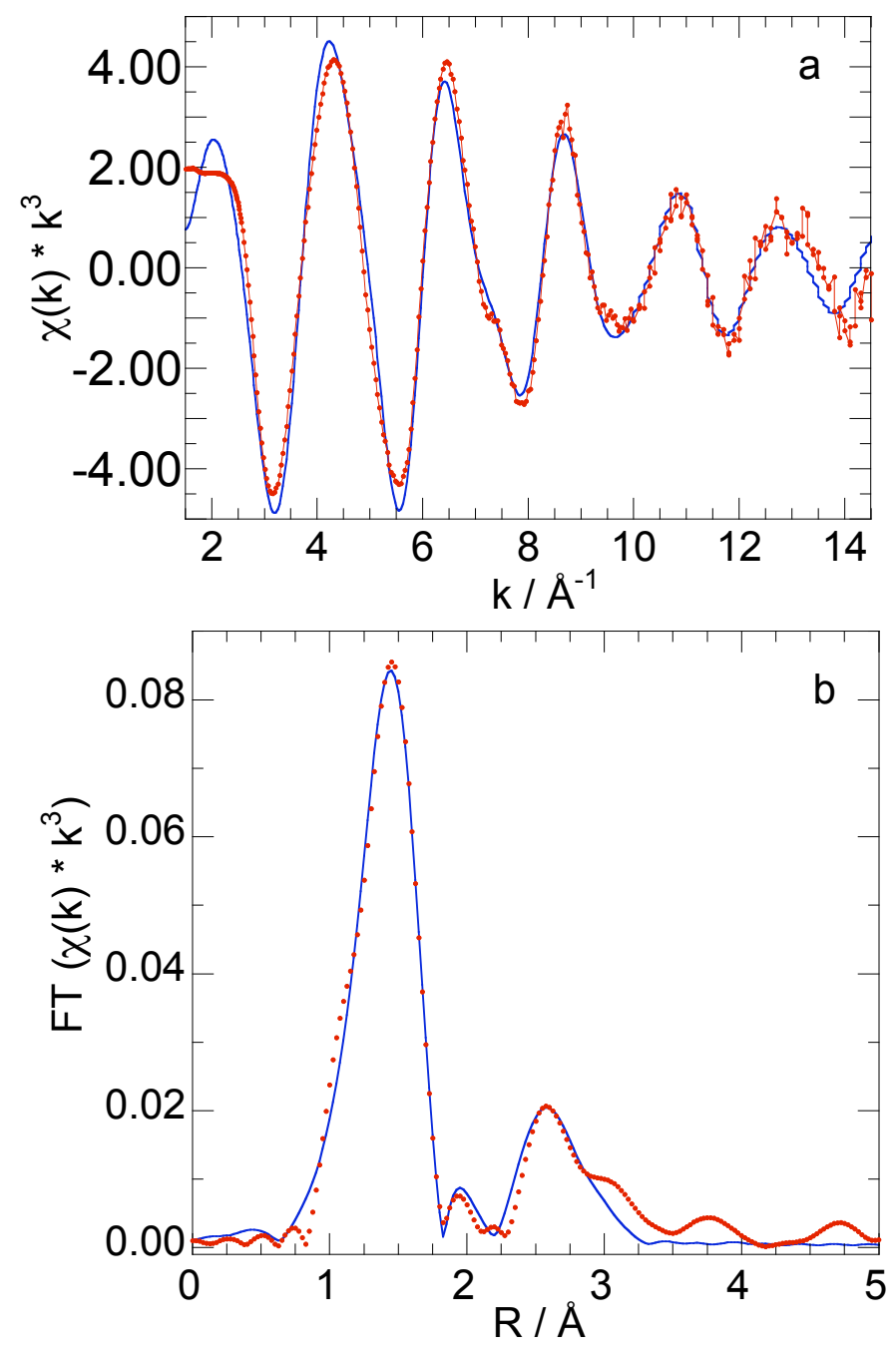

Figure S5. EXAFS data (red points) in $\mathrm{k}^{3}$-weighted $\mathrm{k}$-space (a) and non-phasecorrected R-space (b), for $\left[\mathrm{GaMe}_{2}\left(\mu-\mathrm{OSiPh}_{3}\right)\right]_{2}$. Parameters for the curve-fit including a Ga-Si path (blue lines) are given in Table S4. Note the failure of the model to reproduce the shoulder at $3.1 \mathrm{~A}$.

Table S4. Parameters from the EXAFS curve-fit for $\left[\mathrm{GaMe}_{2}\left(\mu-\mathrm{OSiPh}_{3}\right)\right]_{2}$, as shown in Figure S5, to the single-scattering model based on its XRD structure, including the Ga-Si path. ${ }^{\text {a }}$

\begin{tabular}{lcccc}
\hline path & $\mathrm{N}^{\mathrm{b}}$ & $\mathrm{R}(\AA)$ & $\sigma^{2}\left(\AA^{2}\right)^{\mathrm{b}}$ & $\Delta \mathrm{E}_{0}(\mathrm{eV})$ \\
\hline $\mathrm{Ga}-\mathrm{O}$ & 2 & 1.95 & 0.0036 & 1.68 \\
$\mathrm{Ga}-\mathrm{C}$ & 2 & 1.98 & 0.0068 & 1.02 \\
$\mathrm{Ga}-\mathrm{Ga}$ & 1 & 2.99 & 0.0085 & 0.82 \\
$\mathrm{Ga}-\mathrm{Si}$ & 2 & $3.30^{\mathrm{c}}$ & 0.041 & -7.36 \\
\hline
\end{tabular}

${ }^{\mathrm{a}} \mathrm{S}_{0}{ }^{2}=0.813$. Residual $=5.45$. Note the implausibly large Debye-Waller factor for the Ga-Si path.

${ }^{\mathrm{b}}$ Coordination numbers were fixed at integer values during fit refinement.

${ }^{c}$ Fixed at its crystallographically-determined value during fit refinement. 

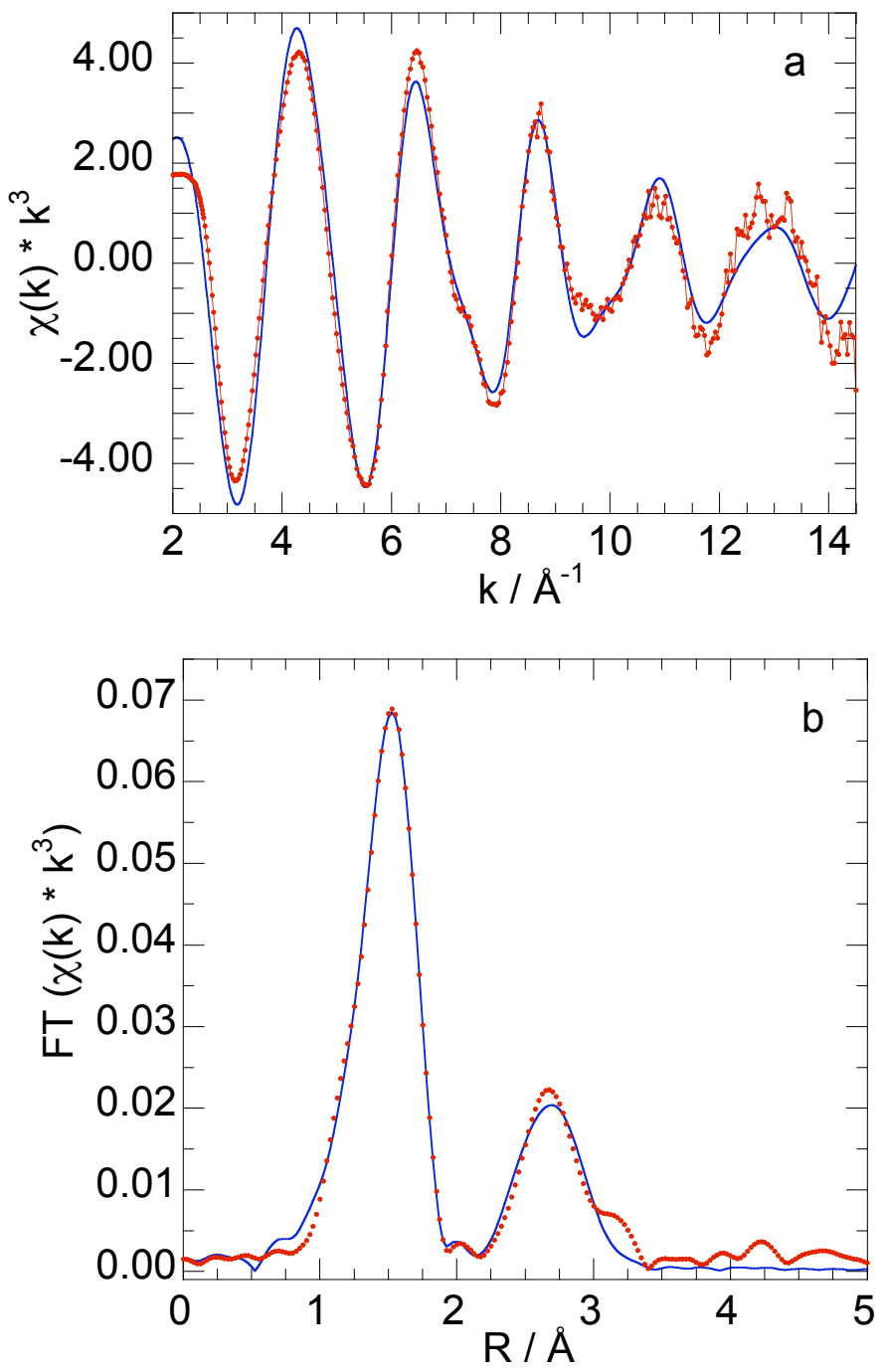

Figure S6. EXAFS data (red points) in $\mathrm{k}^{3}$-weighted k-space (a) and non-phasecorrected R-space (b), for $\mathrm{GaMe}_{3}$-modifed A380-500. Parameters for the curve-fit with refined coordination numbers (blue lines) to model $\mathbf{C}$, $\left[\mathrm{GaMe}_{2}(\mu-\mathrm{OSi} \equiv)\right]_{2}$, are given in Table $\mathrm{S} 5$.

Table S5. Parameters from the EXAFS curve-fit for $\mathrm{GaMe}_{3}$-modifed A380-500, as shown in Figure $\mathrm{S} 6$, to the single-scattering model $\mathbf{C},\left[\mathrm{GaMe}_{2}(\mu-\mathrm{OSi} \equiv)\right]_{2}{ }^{\mathrm{a}}$

\begin{tabular}{lcccc}
\hline path & $\mathrm{N}$ & $\mathrm{R}(\AA)$ & $\sigma^{2}\left(\AA^{2}\right)$ & $\Delta \mathrm{E}_{0}(\mathrm{eV})$ \\
\hline Ga-C & 2.18 & 1.94 & 0.0027 & 1.27 \\
Ga-O & 1.87 & 1.99 & 0.0060 & 1.59 \\
Ga-Ga & 0.96 & 2.98 & 0.0075 & 1.13 \\
\hline
\end{tabular}

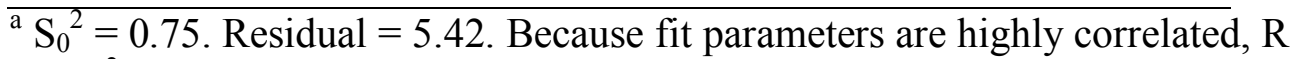
and $\sigma^{2}$ were refined first, then fixed at their fitted values while $\mathrm{N}$ and $\Delta \mathrm{E}_{0}$ were allowed to vary. 

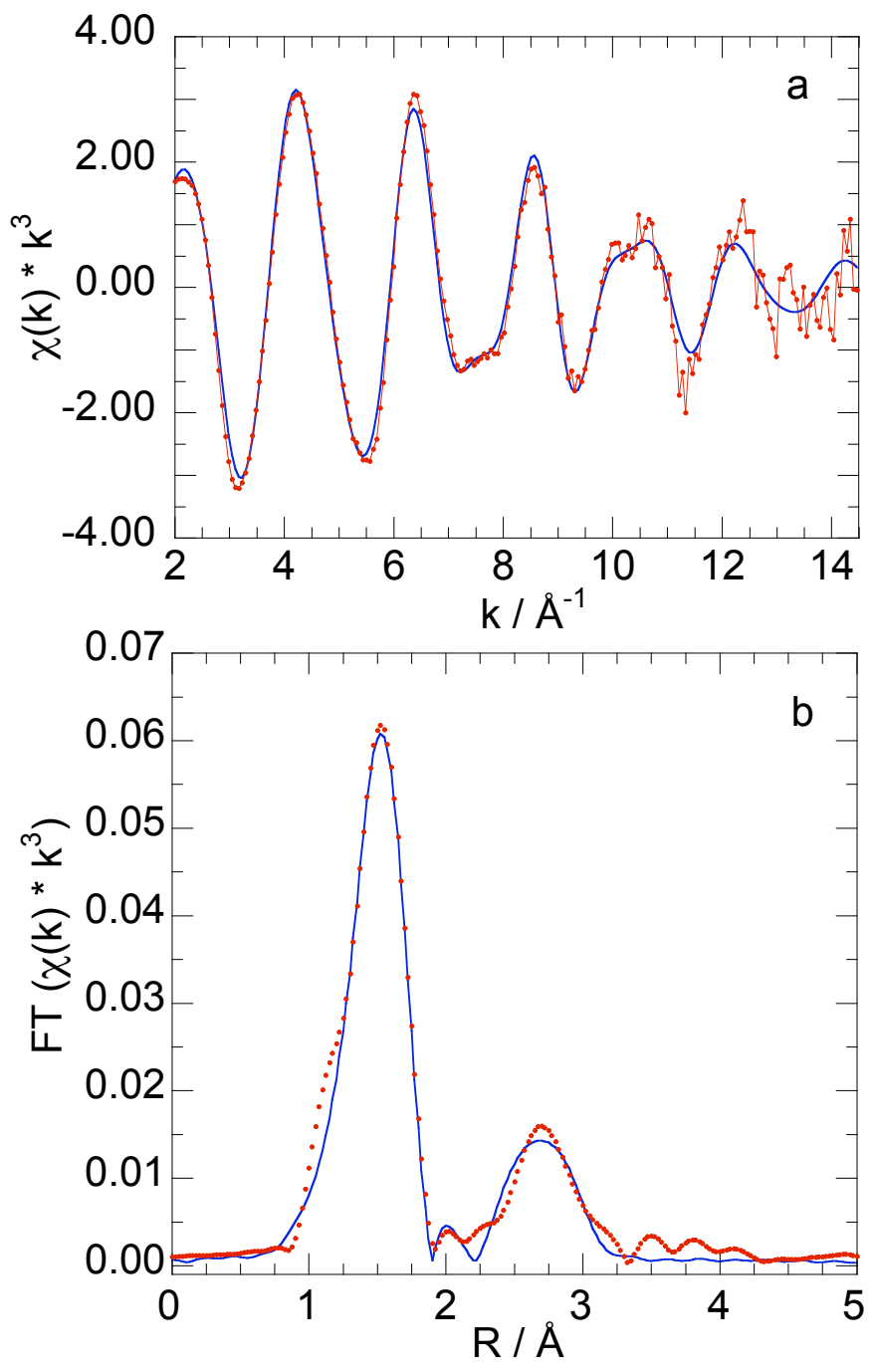

Figure S7. EXAFS data (red points) in $\mathrm{k}^{3}$-weighted k-space (a) and non-phasecorrected R-space (b), for $\mathrm{GaMe}_{3}$-modifed A380-100. Parameters for the curve-fit (blue lines) to model $\mathbf{C},\left[\mathrm{GaMe}_{2}(\mu-\mathrm{OSi} \equiv)\right]_{2}$, are given in Table $\mathrm{S} 6$.

Table S6. Parameters from the EXAFS curve-fit for $\mathrm{GaMe}_{3}$-modifed A380-100, as shown in Figure $\mathrm{S} 7$, to the single-scattering model $\mathbf{C},\left[\mathrm{GaMe}_{2}(\mu-\mathrm{OSi} \equiv)\right]_{2}$.

\begin{tabular}{lcccc}
\hline path & $\mathrm{N}^{\mathrm{b}}$ & $\mathrm{R}(\AA)$ & $\sigma^{2}\left(\AA^{2}\right)$ & $\Delta \mathrm{E}_{0}(\mathrm{eV})$ \\
\hline $\mathrm{Ga}-\mathrm{O}$ & 2 & 1.95 & 0.0045 & 0.65 \\
$\mathrm{Ga}-\mathrm{C}$ & 2 & 1.98 & 0.0071 & -0.35 \\
$\mathrm{Ga}-\mathrm{Ga}$ & 1 & 2.99 & 0.0090 & 1.06 \\
\hline
\end{tabular}

${ }^{\mathrm{a}} \mathrm{S}_{0}^{2}=0.783$. Residual $=6.12$.

${ }^{\mathrm{b}}$ Coordination numbers were fixed at integer values during fit refinement. 